\title{
The Surface Treatment of Niobium Superconducting Reentrant Cavities by Means of High Temperature Nitrogen Plasma Based Ion Implantation
}

\author{
Rogério Moraes Oliveiral ${ }^{\circledR}$ *, Odylio Denys Aguiar ${ }^{1}$, Michel Felipe Lima de Araujo ${ }^{1}$, Matheus M. $N$. \\ F. Silva ${ }^{1}$, Carina B. Mello ${ }^{1}$, Elvis Ferreira ${ }^{1}$, Vincenzo Liccardo' ${ }^{2}$,Graziela da Silva Savonov ${ }^{1}$, Koumei \\ $B a b a^{3}$, Renata Lopes Gonçalves de Souza ${ }^{1}$ \\ ${ }^{1}$ Instituto Nacional de Pesquisas Espaciais, São José dos Campos, SP, Brasil \\ ${ }^{2}$ Instituto Tecnológico de Aeronáutica, São José dos Campos, SP, Brasil \\ ${ }^{3}$ Sanno Co., Ltda - Tsunashima-Higashi, Kohok Yokohama, Shi Kng, Japan
}

Received: April 2, 2019; Revised: September 12, 2019; Accepted: October 28, 2019

\begin{abstract}
High Temperature Nitrogen Plasma Based Ion Implantation (HT-NPBII) has been used to treat the surface of niobium superconducting reentrant cavities, which are part of parametric transducers in a resonant-mass gravitational wave detector. The aim is to enhance the corresponding electrical quality factors (Q-factors) which are closely related with the increase of the sensitivity of the system. In this experiment, the cavities are immersed in plasma and bombarded by energetic nitrogen ions, which are implanted into the surfaces of these heated substrates. The heating temperature of the cavities is controlled during the treatment and its level directly affects the $\mathrm{N}$ implantation depth profile due to the diffusion process. Additional tailoring of the nitrogen doping can be performed by the adjustment of the intensity and the duty cycle of the high negative voltage pulses used for ion implantation. For implantations performed at $5 \mathrm{kV} / 20 \mu \mathrm{s} / 300 \mathrm{~Hz} / 700{ }^{\circ} \mathrm{C}$, nitrogen atoms occupy interstitial spaces in the crystal lattice of niobium. The treatment of niobium superconducting cavities under these parameters caused the enhancement of two orders of magnitude of respective Q-factors. A set of characterization techniques was performed herein in order to help with the understanding of the underlying mechanism behind this phenomenon.
\end{abstract}

Keywords: Niobium, superconducting resonant cavities, plasma ion implantation, gravitational wave detector.

\section{Introduction}

Niobium superconducting reentrant cavities have been used as parametric transducers of the resonant-mass gravitational wave detector Mario Schenberg $[\mathrm{MS}]^{1-2}$, in order to monitor the vibrational state of its massive spherical antenna, which resonates at about $3.2 \mathrm{kHz}\left(f_{0}\right)$. A set of such transducers, coupled to the antenna and pumped through a microwave oscillator at $9.44 \mathrm{GHz}\left(f_{p}\right)$, operates by modulating the capacitance of the reentrant cavities. Therefore, in the presence of specific astrophysical events expected to be detected by MS detector ${ }^{3}$ at $f_{0}$, the microwave signal is then modulated by the antenna mechanical oscillation ${ }^{4-6}$, producing sidebands centered at $f_{\mathrm{p}}$ and displaced by the antenna frequency oscillation, thus indicating the presence of gravitational waves.

Of upmost relevance in this case is the detector sensitivity, associated with the ability to convert extremely small mechanical vibrations of the antenna into electrical signals. Thus, success in this application keeps strong dependence with the performance of the reentrant cavities, measured by the respective quality factors.
Extensive investigation has systematically been accomplished for the improvement of the Q-factors of superconducting niobium cavities, with especial attention devoted to the superconducting RF (SRF) cavities used in particle accelerators ${ }^{7-17}$. In fact, SRF cavity technology had significant progress in the last years, mainly by the introduction of improved surface treatments. In particular, a final boost for a fairly increase of the Q-factors for SRF cavities took place with the development of the nitrogen doping treatment ${ }^{18}$, in which a standardized procedure has been established, involving electro-polishing, baking in ultra high vacuum furnace and the $\mathrm{N}$-doping itself. The objective is to introduce nitrogen atoms as interstitial impurities in the niobium lattice and to avoid the presence of contaminants on the surface of the metal. The findings of such R\&D efforts can also apply to treat the surface of cavities employed in non-accelerating applications, as is the case for the reentrant cavities.

Additionally, it should be considered that the modification of the properties of the surface layer of the cavities, operating at high frequency ranges, can considerably alter their performances. 
In this paper, HT-NPBII has been proposed with the goal of attaining convenient surface modification, able to render high Q-factors for the reentrant cavities operating under cryogenic environment. In this sense, the measured Q-factors were associated with the surface properties of the cavities and with the ion implantation discharge parameters.

PBII is a non-line-of-sight process which can effectively provide $3 \mathrm{D}$ high-energy ion implantation ${ }^{19-20}$, even for substrates with complex geometries. Intrinsic advantages of the method are concerned with the modification of inner layers of $\mathrm{Nb}$, avoiding problems with delamination and dimensional variation. When the substrate is heated with the aid of an auxiliary system during implantation (HT-PBII) ${ }^{21-26}$, the positive ions implanted into the respective surface can reach deeper layers due to thermal diffusion. Through the adjustment of the variables of the process (treatment duration, substrate temperature and the parameters of the high negative voltage pulses used for ion implantation), distinct nitrogen atomic concentration profiles can be attained.

Our findings have translated into significant increase (up two orders of magnitude) in the efficiency of the reentrant cavities used in the MS gravitational wave detector. Result of this research stresses the importance of studying distinct processes for the preparation of the surface of niobium superconducting cavities.

\section{Experimental}

Each cavity-based transducer used in the MS detector features a central conical post and is closed at the top by a flat $\mathrm{Nb}$ circular plate (membrane), which forms a narrow spacing gap (of the order of few micrometers), allowing the cavity to resonate at approximately $9.44 \mathrm{GHz}$, which is the same frequency of the injection source of the external microwave oscillator. The variation of the gap spacing due to the vibration of the membrane (coupled to the antenna) determines the capacitance of this resonant circuit. The geometry of such reentrant cavities (off-scale) is pictured in Fig. 1, where: $\mathrm{R}_{0}=0.5 \mathrm{~mm}$ is the radius of the top of the central conical post; $R_{1}=1.5 \mathrm{~mm}$ is the radius of the base of the conical post; $\mathrm{R}_{2}=7.5 \mathrm{~mm}$ is the internal radius of the cavity; $\lambda=2.95 \mathrm{~mm}$ is the height of the conical post and $\lambda$ ' $=3.0 \mathrm{~mm}$ is the cavity depth. External radius is of $14 \mathrm{~mm}$.

Noteworthy is that the shape of the cavity defines not only its resonance frequency but also strongly influences its Q-factor. In fact, the quality factor is directly proportional to a geometrical constant $(G)$, which is independent on the material properties. Assuming that the surface electrical resistance $\left(R_{s}\right)$ of the cavity does not vary over its surface, a relation between the Q-factor and $G$ can be given by:

$$
Q=\frac{G}{R_{s}}
$$

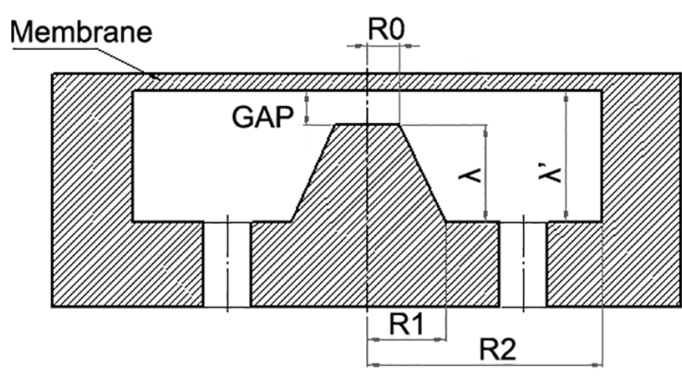

Figure 1. Schematic drawing of the niobium reentrant cavity.

$G$ limits the Q-factors to about $5-7 \times 10^{2}$ for such untreated reentrant cavities, values that are many orders of magnitude lower than the ones attained for SRF cavities used in particle accelerators ${ }^{17,27}$. Though, the quality factors can be enhanced via surface treatment, by reducing the surface resistance $\left(R_{s}\right)$ of the cavity walls, implying in the lowering of the power dissipated by the cavity.

The modification of the surface properties of the reentrant cavities was performed herein via HT-NPBII. This process was recently used to successfully treat $\mathrm{Nb}$ substrates for improving its mechanical and tribological properties ${ }^{28}$ and to enhance its oxidation resistance as well ${ }^{29}$. For both cases, the formation of thick nitride layers, mandatory to reach those proposed goals, was attained thanks to the high substrate temperature adjusted during experiments. On the other hand, the choice for treating the cavities via HT-PBII was determined by the fact that it allows to control the substrate temperature during implantation in a wide range and thus to introduce nitrogen into niobium with very distinct atomic concentration profiles. This was performed by varying the substrate temperatures among experiments from $1200^{\circ} \mathrm{C}$ to $700^{\circ} \mathrm{C}$. The pulse parameters were fixed to $5 \mathrm{kV} / 20 \mu \mathrm{s} / 300 \mathrm{~Hz}$, with exception of the first experiment that run in $1200^{\circ} \mathrm{C}$, for which the pulse intensity was set in $10 \mathrm{kV}$ and the frequency in $500 \mathrm{~Hz}$. One should also consider that in PBII the plasma sheath dimensions of few micrometers are small compared to the substrate feature sizes ${ }^{30-31}$, and then allowing 3D ion implantation, even for complicated shaped objects, as is the particular case of these reentrant cavities. Thus, the nitrogen implantation will take place throughout the surface of the cavities, including their outer and the inner surfaces. This is the main cause precluding the use of conventional ion beam implantation for the purpose exposed herein.

In HT-NPBII the workpiece is immersed in a plasma discharge at $5 \times 10^{-3}$ Torr (density about $10^{8}-10^{9} \mathrm{~cm}^{-3}$ ), being heated by electron bombardment during the off-time of high negative voltage pulses used to implant nitrogen positive ions into the surface of niobium. The precise control of the heating temperature, measured by an optical pyrometer, and the adjustment of the ion implantation energy and duty cycle of the pulses allow to tailoring the nitrogen doping, by controlling the $\mathrm{N}$-implantation depth and its concentration. 
Since the cavities operate at a high frequency range (about $10 \mathrm{GHz}$ ), the skin effect determines that the microwave field penetrates only a few tens of nanometers at the surface of niobium. Thus, the modification of a thin surface layer is imperative to improve the surperconducting properties of the cavities.
The experimental apparatus used to perform HT-NPBII can be seen in Fig. 2a. In this case, the main electron source of the discharge is provided by a low workfunction thermionic emitter ${ }^{32}$. The heating of the substrate can be precisely controlled by varying both, the intensity of the $\mathrm{AC}$ voltage applied to heat the thermionic emitter and the
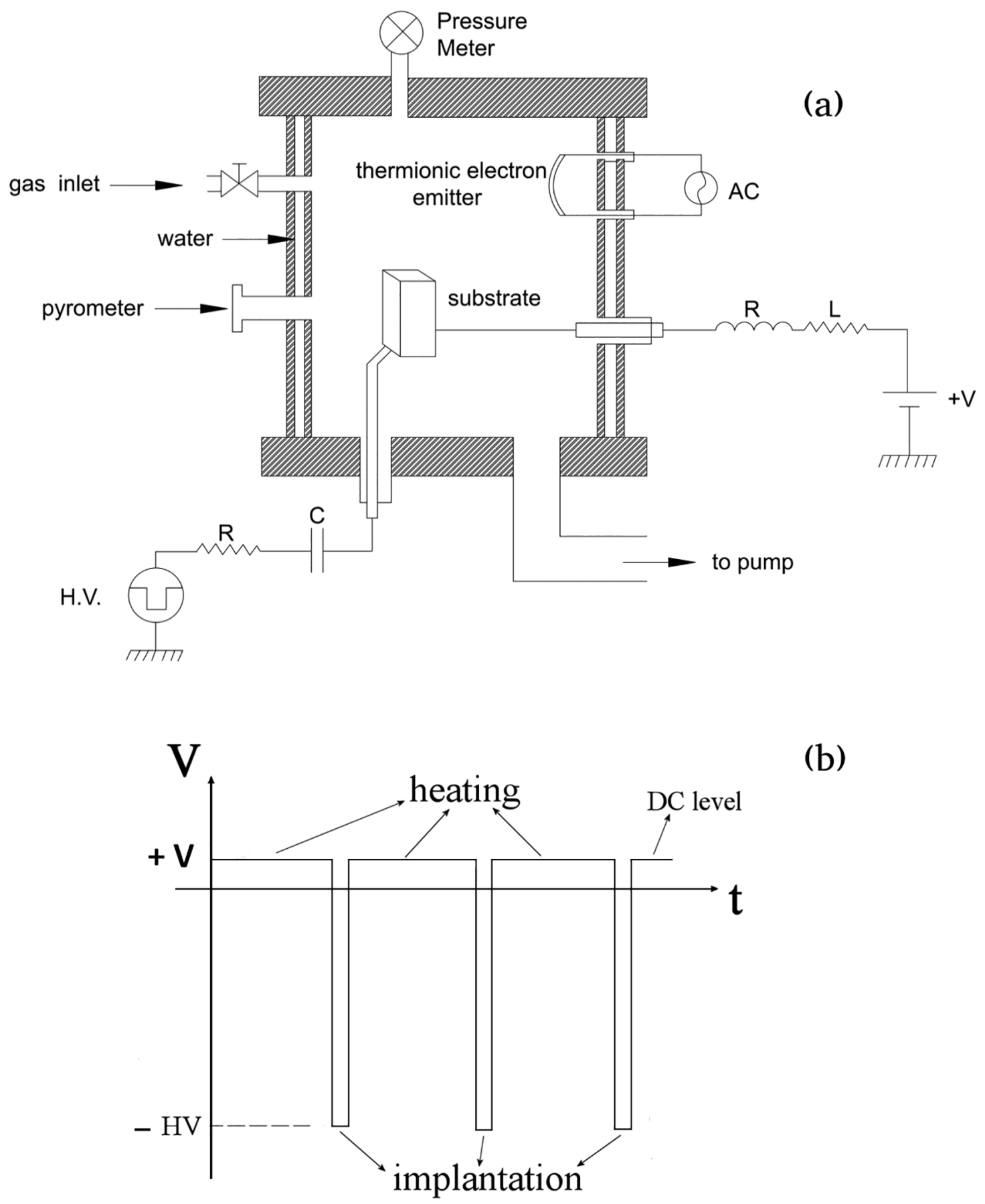

(b)

Figure 2. (a) Experimental apparatus of HT-NPBII; (b) diagram (off-scale) indicating the heating cycle and the ion implantation cycle in a sequence of high negative voltage pulses. 
level of a slightly positive DC voltage $(+\mathrm{V})$ applied to the substrate. Additional heating is provided by the own ion bombardment. The treatment is then comprised of a heating cycle (about $98 \%$ of the duty cycle of the pulse) and an ion implantation cycle in the remaining $2 \%$ of the period, as shown in Fig. $2 b$.

Most of the treatments were first performed in circular samples of high purity niobium (RRR 300), $15 \mathrm{~mm}$ in diameter, used for characterization. Afterwards, selected operation parameters of the ion implantation process were chosen to be replicated to treat the cavities for evaluation of the Q-factors. These samples were polished to a mirror-like finish and cleaned before treatments in ultra-sound bath with acetone for 20 minutes.

The compositional characterization of the surface of the samples was carried out by glancing angle X-ray diffraction (GAXRD), in a high resolution Philips X'Pert diffractometer (standard Bragg-Brentano configuration) with $\mathrm{CuK} \alpha(\lambda=$ $0.154 \mathrm{~nm}$ ) radiation. The grazing incidence angle during measurements was of $2^{\circ}$, allowing to probing depths of typically few hundreds of nanometers. Elemental depth profiles of the modified layers of niobium were attained by glow discharge optical emission spectroscopy (GDOES) and also by Auger electron spectroscopy (AES). For GDOES it was considered an averaged sputtering rate of $4.35 \mu \mathrm{m} / \mathrm{min}$ for $\mathrm{Nb}$ and of $3.45 \mu \mathrm{m} / \mathrm{min}$ for nitride zone. For AES the considered sputtering rate was of $10 \mathrm{~nm} / \mathrm{min}$. The concentration of elements present on the surface of $\mathrm{Nb}$ was also evaluated in certain cases via Energy Dispersive Spectroscopy (EDS). The measurements of the Q-factors were carried out in cryogenic conditions ( $4 \mathrm{~K}$ - liquid helium bath) by inserting electrical probes in the cavities via two circular holes of 3 $\mathrm{mm}$ in diameter. In this case, a signal provided by a vector network analyzer (Agilent 8722/ES) in a pre-defined range is injected into one of the $3 \mathrm{~mm}$ diameter cavity holes, being absorbed in the resonant region of the klystron mode. The reflected signal is then detected by the analyzer. The ratio between the incident and the reflected power at resonance is proportional to the Q-factor, which can also be related by the ratio between the resonance frequency and the frequency bandwidth for half power attenuation $(\Delta f a t-3 \mathrm{~dB})$. This relation, shown in eq. 2 , is valid since the measured reflected power was very small compared to the incident one. Figure 3 illustrates a typical reflection curve at resonance.

$$
Q=\frac{f_{0}}{\Delta f_{3 d B}}
$$

After the machining of the cavities, they were submitted to chemical etching (CE), being dipped in a solution which composition in volume is as follow: $\mathrm{HF}(26 \%), \mathrm{HNO}_{3}(40 \%)$ and $\mathrm{H}_{3} \mathrm{PO}_{4}(34 \%)$. The aim is to remove the first layers of the surface that may have been contaminated during the fabrication process. After the CE, the cavities were washed in de-ionized water. CE was also tested in certain cases as a

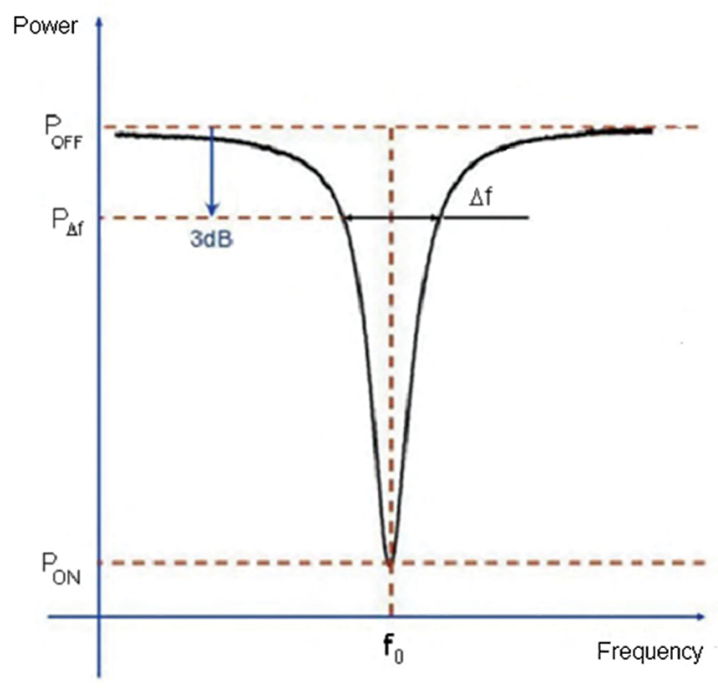

Figure 3. Reflection curve at resonance.

post-implantation stage, in an attempt to avoid that impurities from the processing chamber, mainly oxygen, compromise the cavity performance. In fact, it must be taken into account that oxygen is an impurity hard to be removed from the vacuum chamber, even after conditioning. Additionally, due to the high negative Gibbs free energy for the formation of niobium oxides, even low $\mathrm{O}$ atomic percentages can be sufficient to create oxide clusters, significantly increasing the surface resistance of $\mathrm{Nb}$ with consequent decrease of the Q-factor of the cavities. Another utility of the CE is to serve as a post-implantation tool to control the excess of nitrogen concentration on the surface of $\mathrm{Nb}$, by spalling the outer layers of the treated material. The depth of the etched area of the samples after being dipped in the chemical solution was measured via optical profilometry.

Previously to the nitrogen implantation via HT-NPBII, the samples/cavities were submitted to a cleaning argon glow discharge at $5 \mathrm{kV}$, during 15 minutes, for additional removal of superficial oxides from the metal. The bombardment of inert and heavy argon ions is suitable to remove impurities from the very near surface of niobium.

\section{Results}

The improvement of the superconducting properties of the cavities via surface treatment is indirectly measured by the respective Q-factors, being related with the increase of the signal-to-noise ratio for the detection of gravitational waves in the MS detector.

This investigation began with the idea of producing a superconducting phase on the outermost layer of $\mathrm{Nb}$, with higher critical temperature $\left(\mathrm{T}_{\mathrm{c}}\right)$ than the pure metal. The binary phase diagram of $\mathrm{Nb}-\mathrm{N}$ comprises different superconductive phases $^{33-34}: \alpha$ (solid solution of nitrogen in $\mathrm{Nb}$ ), $\gamma$ (tetragonal $\left.\mathrm{Nb}_{4} \mathrm{~N}_{3}\right)$ and $\delta\left(\mathrm{NaCl}\right.$ structure), with distinct $\mathrm{T}_{\mathrm{c}}$. Among 
them, the one with higher $T_{c}$ (above pure $\mathrm{Nb}$ ) is the phase $\delta$, which requires high nitrogen atomic percentages (over $50 \%$ ) for its formation. Since distinct levels of nitrogen doping (concentration $v s$ depth) can be attained by treating $\mathrm{Nb}$ via HT-NPBII, the discharge parameters were initially set up in order to reach such a high nitrogen concentration on the outermost surface of $\mathrm{Nb}$.

For $\mathrm{Nb}$ samples submitted to pulses of $10 \mathrm{kV} / 20 \mu \mathrm{s} / 500 \mathrm{~Hz}$ and heated at $1200^{\circ} \mathrm{C}$, for $1 \mathrm{~h}$, the attained elemental depth profile shown in Fig. 4 indicates that $\mathrm{N}$-concentration is enough for the formation of the $\delta$ phase for a layer of about $400 \mathrm{~nm}$ in depth from the outer surface. However, for the same analyzed depth range, it is also noticed in Fig. 4 the unwanted presence of contaminants $(\mathrm{C}$ and $\mathrm{O}$ ) with moderate concentrations, enough to impair the superconductivity of the surface. In fact, for the cavities treated under these conditions, very low Q-factors were obtained, even lower than the ones measured for untreated counterparts - about $5 \times 10^{2}$. By examining the respective X-ray diffraction, shown in Fig. 5, it can be observed, in fact, the presence of superconductive phases $\mathrm{NbN}$ (cubic) and $\mathrm{Nb}_{4} \mathrm{~N}_{3}$, but the co-formation of other undesirable phases, like $\mathrm{Nb}_{2} \mathrm{~N}$ and oxinitride of niobium, these last with very low critical temperatures. These findings

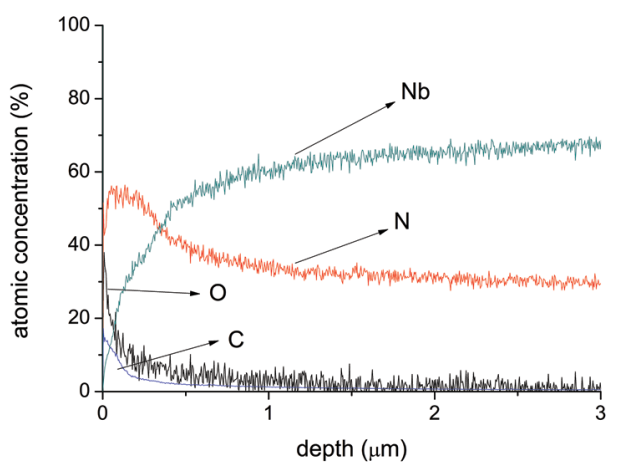

Figure 4. Elemental depth profile for a $\mathrm{Nb}$ sample submitted to pulses of $10 \mathrm{kV} / 20 \mu \mathrm{s} / 500 \mathrm{~Hz}$ and heated at $1200^{\circ} \mathrm{C}$, for $1 \mathrm{~h}$.

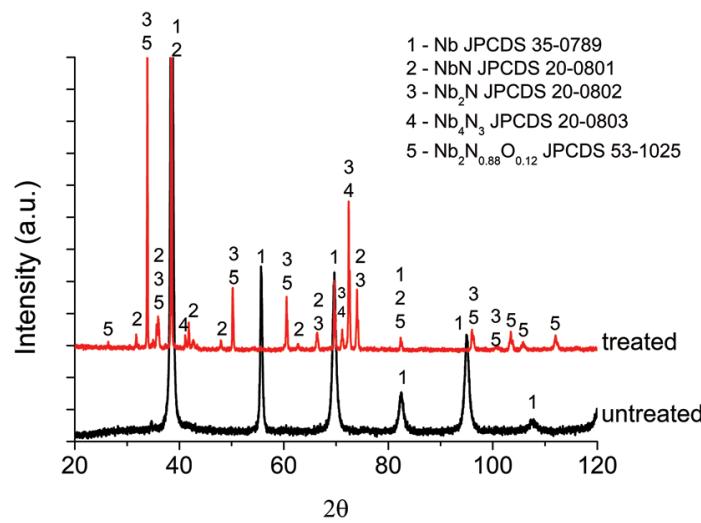

Figure 5. Diffractogram of as-implanted $\mathrm{Nb}$ sample via pulses of $10 \mathrm{kV} / 20 \mu \mathrm{s} / 500 \mathrm{~Hz}$, for $1 \mathrm{~h}$. guided us to the following experimental step, which consisted of submitting such cavities to chemical etching in order to remove the undesired impurities. However, CE was not effective to augment the Q-factors. The thickness of the etched layer was of $0.6 \mu \mathrm{m}$, for cavities dipped in the solution for 10 seconds, that was enough to eliminate the impurities and non-stoichiometric phases, but also totally suppressing the desirable $\mathrm{NbN}$ phase (present at depth up to $0.4 \mu \mathrm{m}$ from the surface). A partial conclusion was the impossibility to form the superconductive $\delta$-NbN phase layer without the co-formation of unwanted phases via HTPBII and chemical etching for the set operation parameters.

In the pioneering paper of Grasselino et al ${ }^{18}$ it was reported that the augment of Q-factor for SRF cavities used in particle accelerators was related with the insertion of $\mathrm{N}$ in the interstices of the $\mathrm{Nb}$ lattice, avoiding the formation of $\mathrm{Nb}_{\mathrm{x}} \mathrm{N}_{\mathrm{y}}$ phases. Therefore, in order to prevent the constitution of these nitrides, the operation parameters of the ion implantation discharge were attenuated for the experiments that followed. In a first step, the temperature was reduced to $1050{ }^{\circ} \mathrm{C}$ and the treatment duration to $15 \mathrm{~min}$, with the application of pulses of $5 \mathrm{kV} / 20 \mu \mathrm{s} / 300 \mathrm{~Hz}$. Though, the resulting $\mathrm{X}$-ray diffractogram shown in Fig. 6(a) once again indicated the presence of several unwanted $\mathrm{Nb}_{\mathrm{x}} \mathrm{N}_{\mathrm{y}}$ phases $\left(\mathrm{Nb}_{2} \mathrm{~N}, \mathrm{NbN}_{0.801}, \mathrm{Nb}_{5} \mathrm{~N}_{6}, \mathrm{NbN}_{0.95}\right)$. After chemical etching under the same previous conditions, however, there was a significant change in the diffractogram, as can be seen in Fig. 6(b), in which only $\mathrm{Nb}$ peaks were detected. Noticeable is that the resulting Q-factors still remained low, indicating that the removal of nitride peaks seems not to be the only condition to be persecuted in order to increase the performance of the cavities. It seems that an optimal proportion of $\mathrm{N} / \mathrm{Nb}$ is required to be attained on the outermost surface of $\mathrm{Nb}$ in order to elevate the Q-factor. In fact, as previously stated by Grasselino et al. ${ }^{18,35}$, excessive nitrogen content may degrade the Q-factors of niobium SRF cavities. Therefore, a milder nitrogen-doping treatment via HT-NPBII should be performed. This could be accomplished by both, the change of the parameters of HTPBII and/or the conditions of the chemical attack, which is related with the material removal. The decision was to proceed reducing even more the temperature, now to $900^{\circ} \mathrm{C}$, while keeping constant the other discharge parameters. The $\mathrm{N}$ concentration measured by AES for this new condition decreased significantly in comparison with treatments performed at $1200^{\circ} \mathrm{C}$ and remained almost stable and near 5\% in the investigated depth range, as shown in Fig. 7, consistent with the formation of $\alpha+\beta$ phase, according to the $\mathrm{Nb}-\mathrm{N}$ phase diagram ${ }^{33}$. This condition led to the raise of Q- factors from about 500 for the untreated cavities to about 830 after ion implantation and to 11,400 after additional chemical etching. The correspondent $\mathrm{Q}$ increase can be related with the low $\mathrm{N}$ at. \% detected in this case, in which a more favorable $N / N b$ ratio for the enhancement of the Q-factors was attained. In addition, the etching seemed 

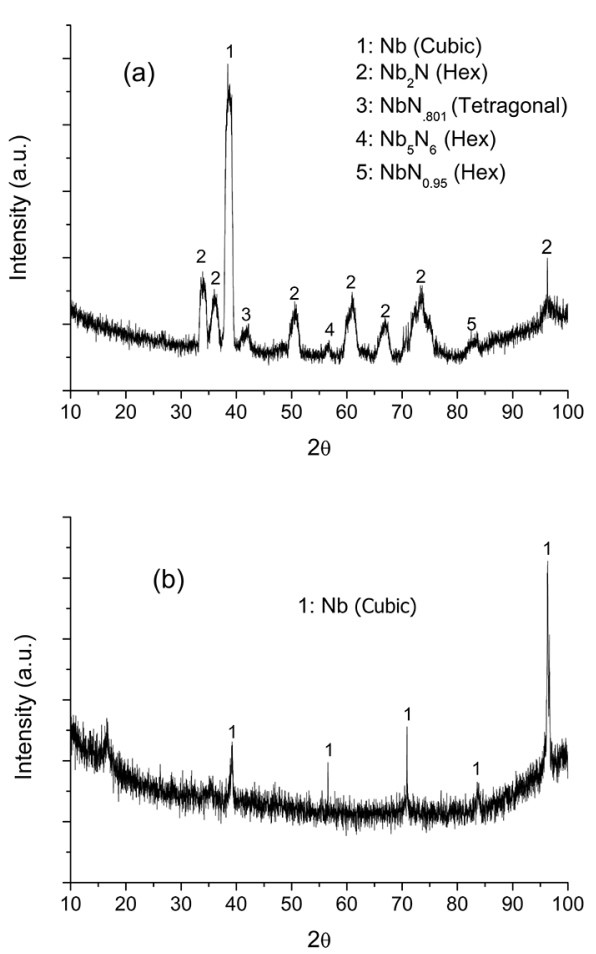

Figure 6. $\mathrm{XRD}$ for $\mathrm{Nb}$ sample heated at $1050{ }^{\circ} \mathrm{C}$ and treated via pulses of $5 \mathrm{kV} / 20 \mu \mathrm{s} / 300 \mathrm{~Hz}$, for $15 \mathrm{~min}$. (a) before chemical etching, (b) after chemical etching.

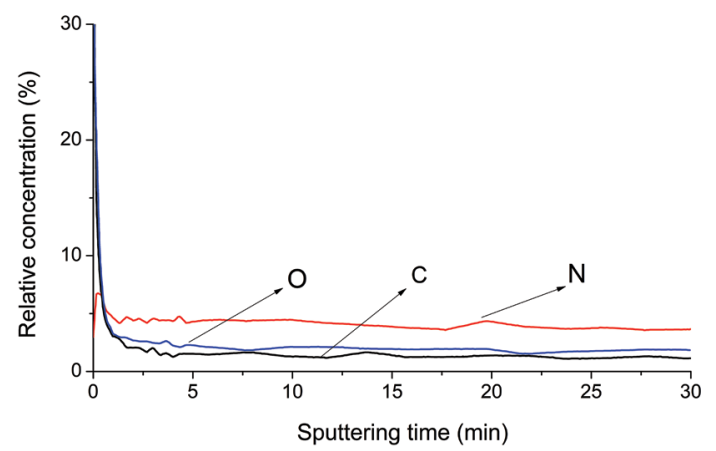

Figure 7. Elemental depth profile for a $\mathrm{Nb}$ sample submitted to pulses of $5 \mathrm{kV} / 20 \mu \mathrm{s} / 300 \mathrm{~Hz}$, heated at $900{ }^{\circ} \mathrm{C}$, for $15 \mathrm{~min}$.

to be effective to remove the impurities, corroborating with the increase of the Q-factor. The premise of a surface free of nitride phases was attained for this treatment condition after chemical etching, as shown in the diffractogram of Fig. 8.

As the next investigation procedure, further reduction in temperature, now to $700{ }^{\circ} \mathrm{C}$, was established, without changing any other discharge parameters. Respective diffractogram shown in Fig. 9 still indicates the presence of $\mathrm{Nb}_{2} \mathrm{~N}$ and a small peak of $\mathrm{NbN}_{0.64}$, but with the suppression of other nitride peaks. After chemical etching, only cubic $\mathrm{Nb}$ was detected. For this treatment condition, Q-factor raised from 5,800 before chemical etching to 60,000 afterwards. This time, nitrogen content after CE, of about $2.1 \%$, was

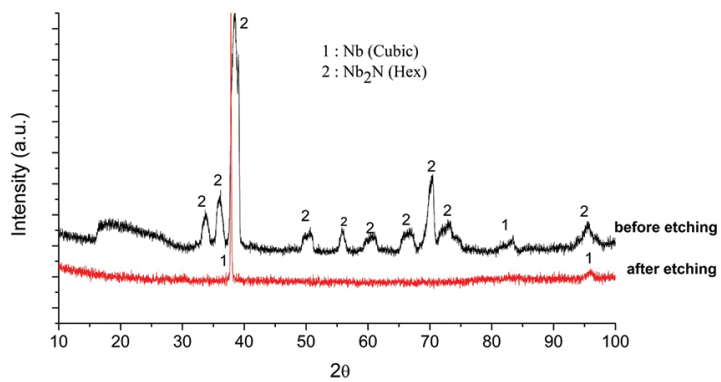

Figure 8. $\mathrm{XRD}$ for $\mathrm{Nb}$ sample heated at $900^{\circ} \mathrm{C}$ and treated via pulses of $5 \mathrm{kV} / 20 \mu \mathrm{s} / 300 \mathrm{~Hz}$, for $15 \mathrm{~min}$., before and after chemical etching.

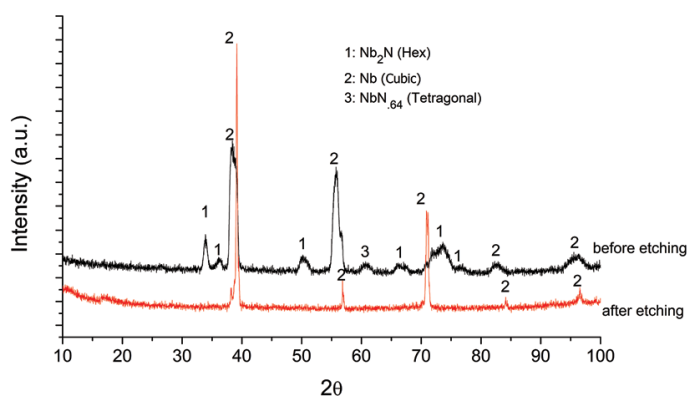

Figure 9. $\mathrm{XRD}$ for $\mathrm{Nb}$ sample heated at $700^{\circ} \mathrm{C}$ and treated via pulses of $5 \mathrm{kV} / 20 \mu \mathrm{s} / 300 \mathrm{~Hz}$, for $15 \mathrm{~min}$., before and after chemical etching.

measured by EDS at the top of the conical post of the cavity. This corresponds to the $\alpha$-phase, in which nitrogen is in solid solution in niobium. It seems that the $N / N b$ proportion for this case is closer to an optimal ratio, due to the high Q- factor attained for this condition. In a rough estimative, taking into consideration the niobium density of $8.57 \mathrm{~g} /$ $\mathrm{cm}^{3}$, corresponding to approximately $5.54 \times 10^{22}$ niobium atoms $/ \mathrm{cm}^{3}$, the measured nitrogen concentration of $2.1 \%$ indicates a density of about $1.16 \times 10^{21}$ nitrogen atoms $/ \mathrm{cm}^{3}$ on the surface of the metal.

Table 1 summarizes all the ion implantation experiments performed in this investigation, in which the Q-factor of the cavities was enhanced from about 500 to 60,000 , representing an increase of two orders of magnitude. The higher Q-factors $(11,400$ and 60,000$)$ were attained for surfaces free from niobium nitrides and oxynitrides. It seems that the reduction of the ratio $\mathrm{N} / \mathrm{Nb}$ favored the achievement of higher Q-factors.

After this series of ion implantation experiments, it seems that further increments of the Q-factors for the niobium reentrant cavities can be achieved, by exploring additional experimental HT-PBII parameters, in order to address a more accurate correlation between the concentration of nitrogen atoms implanted on the surface of the cavities with the respective Q-factors.

\section{Summary}

Nitrogen ion implantation performed via HTPBII and associated with chemical etching was effective to increase 
Table 1. Correlation between ion implantation parameters and respective Q-factors of niobium reentrant cavities, showing the phases detected by XRD and whether the chemical attack was or not performed. The experimental condition that changed compared to the previous treatment is underligned.

\begin{tabular}{|c|c|c|c|}
\hline Treatment parameters & Chemical etching & Detected phases & Q- factors \\
\hline $10 \mathrm{kV} / 20 \mu \mathrm{s} / 500 \mathrm{~Hz} ; 1200^{\circ} \mathrm{C} ; 1 \mathrm{~h}$ & No & $\mathrm{Nb}, \mathrm{NbN}, \mathrm{Nb}_{4} \mathrm{~N}_{3}, \mathrm{Nb}_{2} \mathrm{~N}, \mathrm{Nb}_{2} \mathrm{~N}_{0.88} \mathrm{O}_{0.12}$ & $<500$ \\
\hline $10 \mathrm{kV} / 20 \mu \mathrm{s} / 500 \mathrm{~Hz} ; 1200^{\circ} \mathrm{C} ; 1 \mathrm{~h}$ & Yes & $\mathrm{Nb}$ & $<500$ \\
\hline $5 \mathrm{kV} / 20 \mu \mathrm{s} / 300 \mathrm{~Hz} ; 1050^{\circ} \mathrm{C} ; 15 \mathrm{~min}$. & No & $\begin{array}{l}\mathrm{Nb}_{2} \mathrm{~N}, \mathrm{NbN}_{0.801} \\
\mathrm{Nb}_{5} \mathrm{~N}_{6}, \mathrm{NbN}_{0.95}\end{array}$ & 500 \\
\hline $5 \mathrm{kV} / 20 \mu \mathrm{s} / 300 \mathrm{~Hz} ; 1050{ }^{\circ} \mathrm{C}, 15 \mathrm{~min}$. & Yes & $\mathrm{Nb}$ & 500 \\
\hline $5 \mathrm{kV} / 20 \mu \mathrm{s} / 300 \mathrm{~Hz} ; 900^{\circ} \mathrm{C}, 15 \mathrm{~min}$. & No & $\mathrm{Nb}, \mathrm{Nb}_{2} \mathrm{~N}$ & 830 \\
\hline $5 \mathrm{kV} / 20 \mu \mathrm{s} / 300 \mathrm{~Hz} ; 900^{\circ} \mathrm{C}, 15 \mathrm{~min}$ & Yes & $\mathrm{Nb}$ & 11400 \\
\hline $5 \mathrm{kV} / 20 \mu \mathrm{s} / 300 \mathrm{~Hz} ; 7^{\circ}{ }^{\circ} \mathrm{C}, 15 \mathrm{~min}$. & No & $\mathrm{Nb}, \mathrm{Nb}_{2} \mathrm{~N}, \mathrm{NbN}_{0.64}$ & 5800 \\
\hline $5 \mathrm{kV} / 20 \mu \mathrm{s} / 300 \mathrm{~Hz} ; 700^{\circ} \mathrm{C}, 15 \mathrm{~min}$. & Yes & $\mathrm{Nb}$ & 60,000 \\
\hline
\end{tabular}

* Q-factor for pristine $\mathrm{Nb}$ cavity is about 500 .

the Q-factors of superconducting reentrant niobium cavities up to two orders of magnitude. This enhancement was attained by eliminating contaminants and by controlling the $\mathrm{N}$ concentration on the surface of niobium, in order to avoid the formation of niobium nitrides. A sweep of the operation parameters was performed to attain distinct $N / N b$ ratios, in order to correlate this data with the Q-factor of the cavities. The highest $\mathrm{Q}$ factor was reached for low $\mathrm{N}$ concentration on the niobium surface, corresponding to the $\alpha$-phase in the $\mathrm{Nb}-\mathrm{N}$ phase diagram.

A more systematic and extensive investigation is demanded, in order to correlate the different levels of nitrogen dissolved into $\mathrm{Nb}$ surface with the Q-factor of the cavities. This can be accomplished by strictly monitoring the $\mathrm{N}$ concentration after every new experimental step, including ion implantation and chemical etching. Thus, further enhancement of the Q-factors for such reentrant cavities can be achieved with the optimization of the operation parameters of HT-NPBII. The findings of this research can also be considered in the future as an alternative method for the treatment of niobium SRF cavities, as the ones used in particle accelerators.

\section{Acknowledgements}

This work is supported by the National Council for Scientific and Technological Development (CNPq) through the process 423450/2016-6 and the State of São Paulo Research Foundation (FAPESP), under the Regular Project 2017/01436-8.

\section{References}

1. Aguiar OD, Andrade LA, Barroso JJ, Bortoli F, Carneiro LA, Castro PJ, et al. Classical and Quantum Gravity. INPE - Ciências Espaciais e Atmosféricas. 2002;19(7):1949-1953.

2. Pimentel GL, Aguiar OD, Barroso JJ, Tobar ME. Investigation of ultra-high sensitivity klystron cavity transducers for broadband resonant-mass gravitational wave detectors. Journal of Physics: Conference Series. 2008;122:012028.
3. Aguiar OD, Araújo JCN, Miranda OD, Velloso WFJR. Prováveis fontes candidatas à observação pelo detector de ondas gravitacionais “Mario Schenberg”. In: Reunião Anual Da Sociedade Astronômica Brasileira; 1999; Caxambu (MG), Brasil. Caxambu: Anais da Sociedade Astronômica Brasileira. 1999;19(1):35.

4. Aguiar OD, Barroso JJ, Carvalho NC, Castro PJ, Cedeño CE, Costa CFS, et al. Status report of the schenberg gravitational wave antenna. Journal of Physics: Conference Series. 2012;363(1):012003.

5. Aguiar OD. The past, present and future of the resonant-mass gravitational wave detectors. TechnicaReport [Internet]. 2010; [aprox.49 telas]. Available from: https://arxiv.org/ftp/arxiv/ papers/1009/1009.1138.pdf

6. Tobar ME, Ivanov EN, Blair DG. Parametric transducers for the advanced cryogenic resonant-mass gravitational wave detectors. General Relativity and Gravitation. 2000;32(9):1799-1821.

7. Llje L. Overview on high field Q-Slope. In: Kim KJ, Eyberger $\mathrm{C}$, editors. Proceedings of the Workshop on Pushing the Limits of RF Superconductivity. Argonne: ANL; 2015. p. 43-51.

8. Ciovati G. High Q at Low and Medium Field. In: Kim KJ, Eyberger C, editors. Proceedings of the Workshop on Pushing the Limits of RF Superconductivity. Argonne: ANL; 2015. p. 52-64.

9. Antoine CZ. Overview of surface measurements: what do surface studies tell us about Q-Slope?. In: Kim KJ, Eyberger $\mathrm{C}$, editors. Proceedings of the Workshop on Pushing the Limits of RF Superconductivity. Argonne: ANL; 2015. p. 65-72.

10. Visentin B. Low, medium, high field Q-Slopes change with surface treatments. In: Kim KJ, Eyberger C, editors. Proceedings of the Workshop on Pushing the Limits of RF Superconductivity. Argonne: ANL; 2015. p. 94-105.

11. Reece CE, Ciovati G. Superconducting radio-frequency technology R\&D for future accelerator applications. Reviews of Accelerator Science and Technology. 2012;5:285-312.

12. Kelly M. Superconducting radio-frequency cavities for lowbeta particle accelerators. Reviews of Accelerator Science and Technology. 2012;5:185-203.

13. Weingarten W. Field-dependent surface resistance for superconducting niobium accelerating cavities. Physical Review ST Accelerators and Beams. 2011;14(10):101002. 
14. Lin FPJ, Gurevich A. Effect of impurities on the superheating field of type-II superconductors. Physical Review: B. 2012;85(5):054513.

15. Padamsee H. Superconductivity: Science, Technology and Applications. Weinheim: WileyVCH; 2009. v. 2.

16. Dhakal P, Ciovati G, Myneni GR, Gray KE, Groll N, Maheshwari $\mathrm{P}$, et al. Effect of high temperature heat treatments on the quality factor of a large-grain superconducting radio-frequency niobium cavity. Physical Review ST Accelerators and Beams. 2013;16(4):042001.

17. Ciovati G, Dhakal P, Gurevich A. Decrease of the surface resistance in superconducting niobium resonator cavities by the microwave field. Applied Physics Letters. 2014;104:092601.

18. Grassellino A, Romanenko A, Melnychuk O, Trenikhina Y, Crawford AC, Rowe A, et al. Nitrogen and argon doping of niobium for superconducting radio frequency cavities: a pathway to highly efficient accelerating structures. Superconductor Science and Technology. 2013;26(10):102001.

19. Conrad JR, Radtke JL, Dodd RA, Worzala FJ, Tran NC. Plasma source ion-implantation technique for surface modification. Journal of Applied Physics. 1987;62(11):4591-4596.

20. Conrad JR. Plasma source ion implantation: A new approach to ion beam modification of materials. Materials Science and Engineering: A. 1989;116:197-203.

21. Oliveira RM, Mello CB, Silva G, Gonçalves JAN, Ueda M, Pichon L. Improved properties of Ti6Al4V by means of nitrogen high temperature plasma based ion implantation. Surface and Coatings Technology. 2011;205(Suppl 2):S111-S114.

22. Carreri FC, Oliveira RM, Capella A, Silva MMNF, Ueda M, Silva MM, et al. Phase formation and mechanical/tribological modification induced by nitrogen high temperature plasma based ion implantation into molybdenum. Applied Surface Science. 2014;310:305-310.

23. Oliveira AC, Oliveira RM, Reis DAP, Carreri FC. Effect of nitrogen high temperature plasma based ion implantation on the creep behavior of Ti-6Al-4V alloy. Applied Surface Science. 2014;311:239-244.

24. Oliveira RM, Fernandes BB, Carreri FC, Gonçalves JAN, Ueda M, Silva MMNF, et al. Surface modification of NiTi by plasma based ion implantation for application in harsh environments. Applied Surface Science. 2012;263:763-768.
25. Fernandes BB, Mändl S, Oliveira RM, Ueda M. Mechanical properties of nitrogen-rich surface layers on SS304 treated by plasma immersion ion implantation. Applied Surface Science. 2014;310:278-83.

26. Fernandes BB, Oliveira RM, Oliveira RM, Ueda M, Mariano SFM, Ramos AS, et al. Effects of high temperature plasma immersion ion implantation on wear resistance of Ti-Si-B sintered alloys. Surface and Coatings Technology. 2013;228:195-200.

27. Dhakal P, et al. Effect of high temperature heat treatments on the quality factor of a large-grain superconducting radio-frequency niobium cavity. Phys. Rev. ST-AB. 2013;16:042001. - ref é igual a n. 16.

28. Oliveira RM, Oliveira AC, Carreri FC, Gomes GF, Ueda M, Silva MMNF, et al. Detailed surface analyses and improved mechanical and tribological properties of niobium treated by high temperature nitrogen plasma based ion implantation. Applied Surface Science. 2013;283:382-388.

29. Oliveira RM, Hoshida L, Oliveira AC, Silva MMNF, Pichon L, Santos NM. Evaluation of the resistance to oxidation of niobium treated by high temperature nitrogen Plasma Based Ion Implantation. Surface and Coatings Technology. 2017;312:110116. DOI: https://doi.org/10.1016/j.surfcoat.2016.10.012

30. Anders A. Handbook of Plasma Immersion Ion Implantation and Deposition. New York: John Wiley \& Sons; 2000.

31. Anders A. From plasma immersion ion implantation to deposition: a historical perspective on principles and trends. Surface and Coatings Technology. 2002;156(1):3-12.

32. Oliveira RM, Gonçalves JAN, Ueda M, Rossi JO, Rizzo PN. A new high-temperature plasma immersion ion implantation system with electron heating. Surface and Coatings Technology. 2010;204(18-19):3009-3012.

33. Brauer G, Esselborn R. Nitridphasen des Niobs, Zeitschrift für anorganische und allgemeine. Journal of Inorganic and General Chemistry. 1961;309(3-4):151-170.

34. Musenich R, Fabbricatore P, Gemme G, Parodi R, Viviani M, Zhang B, et al. Growth of niobium nitrides by nitrogen-niobium reaction at high temperature. Journal of Alloys and Compounds. 1994;209(1-9):319-328.

35. Grassellino A, Romanenko A, Posen S, Trenikhina Y, Melnychuk $\mathrm{O}$, Sergatskov D, et al. $\mathrm{N}$ doping: progress in de-velopment and understanding. In: Proceedings of the 17th International Conference on RF Superconductivity. Whistler, BC, Canada; 2015. Whistler, BC: MOBA06; 2015. p. 48-54. 